\title{
The Turin Conference on Working-Class Culture
}

\section{Sean Wilentz \\ Princeton University}

The problematical history of working-class culture-the importance of culture in shaping and defining class relations, the very meaning of the term-continues to vex social and labor historians. Having begun, with great enthusiasm, the rediscovery of the lived experience and cultural resources of laboring men and women, we now find ourselves caught in several theoretical and empirical tangles. Attempts to resolve some of these problems, concerning gender, the fitfulness and unevenness of cultural change, the relationship of culture to the exercise of political power, have led to some of the most bracing debates of the last few years.

From May 27-30, 1982, more than seventy scholars, most of them from Western Europe, gathered in Turin to discuss this ongoing work at a conference entitled, "La cultura operaia nella società industrializzata." Sponsored by the Centro Studi Piero Gobetti, the conference was something of an extravaganza. Topics ranged widely, from reports on recent work in various countries to detailed research papers. No session heard fewer than three presentations; some heard as many as five. In addition to the regular meetings, delegates were treated to a round of concerts, exhibitions, and informal get-togethers. It was a stimulating-if exhausting-time; regrettably, formal debate was limited to an hour or so on the final afternoon.

A few themes reappeared through it all, and were ably summarized at the closing commentary session led by Geoffrey Crossick, Yves Lequin, and Michelle Perrot. The first concerned a general malaise about what historians expect to accomplish when they study the cultural lives of working people. With the fragmentation of the Annales school and the study of mentalite, and with the variety of Marxist and sociological approaches now employed, we sometimes seem to be making radically different kinds of statements about similar topics. Although there were persistent hints that recent "anthropological" historical work established fruitful lines of inquiry, there was no agreement about how anthropological methods could be adapted to the objects and sources available to most historians. Even if such agreement were possible, meanwhile, it was not altogether clear where the boundaries of working-class culture should be set, since so much of what historians 
label "working-class" turns out, on close examination, to be far less class-specificeither "plebeian," or some permutation of urban and peasant cultures. The lesson here, the commentators stressed, should not be to turn the question around, to say that the lack of a "pure" proletarian way of life signified the acquiescence or cultural poverty of wage-earning men and women: rather, it is important not to reify the subject and abstract working-class cultural life from historical process.

The strongest point-echoing the work of E. P. Thompson, Bryan Palmer, and others, and emphasized by Crossick - was an insistence that any study of working-class culture assumes historical meaning only in the context of conflict and struggle. To turn to the experience of workers' lives, their changing conceptions of space, time, family, community, and so forth, is to open new vistas on the history of class relations; what matters in the end, however, is how these experiences were bound up with the process of class definition and social change. Although a familiar theme, especially to Anglo-American historians, it seemed an appropriate note on which to conclude such a multifarious program.

There were, to an American's eyes, some omissions from the conference: only one research paper, for example, discussed the intersection of class and gender, a sign of some of the differences in the concerns of the English and Americans and those of their Continental colleagues. At the same time, however, the program was a cornucopia of recent work and work-in-progress, particularly on France, Italy, and West Germany. Eighteenth-century popular culture and workers' experience were discussed in especially noteworthy contributions by Roger Chartier and Daniel Roche; several papers illuminated the political culture of different labor movements.

The Gobetti Center is to be congratulated for this ambitious undertaking. The published conference proceedings (due in late 1982) ought to bring the conference into sharper focus than was possible in Turin. They will certainly be an important resource for Americans who wish to learn more about the state of the field abroad. 